\title{
Involvement of Phosphatidylinositol 4,5-Bisphosphate in the Desensitization of Canonical Transient Receptor Potential 5
}

\author{
Byung Joo KIm, ${ }^{a}$ Min Tae KIm, ${ }^{a}$ Ju-Hong JeON, ${ }^{a}$ Seon Jeong KIm, ${ }^{b}$ and Insuk So ${ }^{*, a}$ \\ ${ }^{a}$ Center for Bio-Artificial Muscle and Department of Physiology, Seoul National University College of Medicine; Seoul \\ 110-799, Korea: and ${ }^{b}$ Center for Bio-Artificial Muscle and Department of Biomedical Engineering, Hanyang University; \\ Seoul 133-791, Korea. Received March, 31, 2008; accepted June 4, 2008; published online June 26, 2008
}

\begin{abstract}
The classic transient receptor potential channel (TRPC) is a candidate for $\mathrm{Ca}^{2+}$-permeable cation channel in mammalian cells. TRPC5 is desensitized rapidly after activation by $G$ protein-coupled receptor. Here we investigate the mechanisms of desensitization of TRPC5 using patch-clamp recording. TRPC5 was initially activated by muscarinic stimulation using $50 \mu \mathrm{M}$ carbachol $(\mathrm{CCh})$ and decayed rapidly in the presence of $\mathrm{CCh}$ (desensitization). Intracellularly-applied phosphatidylinositol 4,5-bisphosphate $\left(\mathrm{PIP}_{2}\right)$ slowed the rate of desensitization. In contrast, several other phosphoinositides, including $\mathrm{PI}(3,4) \mathrm{P}_{2}, \mathrm{PI}(3,5) \mathrm{P}_{2}, \mathrm{PI}(3,4,5) \mathrm{P}_{3}$ and $\mathrm{PI}(4) \mathrm{P}$, had no effect on the desensitization of the TRPC5 current. This indicates that PIP ${ }_{2}$ attenuates the desensitization of the TRPC5 current in a highly selective manner. Neither wortmannin, an inhibitor of phosphatidylinositol 4-kinase, or polyL-lysine (PLL), a scavenger of PIP ${ }_{2}$, had any effect on desensitization of the TRPC5 current. PIP ${ }_{2}$ breakdown ap-

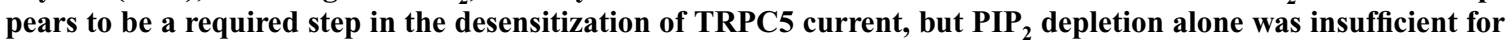
channel desensitization. TRPC5 was inhibited by cytochalasin D treatment. In mouse ileal myocytes, the desensitization of $\mathrm{CCh}$-activated inward current $\left(I_{\mathrm{CCh}}\right)$ also slowed in the presence of $\mathrm{PIP}_{2}$ in recording pipettes. These results indicate that $\mathrm{PIP}_{2}$ is involved in the desensitization of TRPC5 currents.
\end{abstract}

Key words canonical transient receptor potential 5; muscarinic stimulation; phosphatidylinositol 4,5-bisphosphate

The classic transient receptor potential channel (TRPC) is likely to be a $\mathrm{Ca}^{2+}$-permeable cation channel in mammalian cells. Five different TRPC channels have been isolated. Among them, TRPC5 was initially hypothesized to be a store-operated channel $(\mathrm{SOC})^{1)}$; however, it was then shown to be activated by stimulating $G$ protein-coupled receptors (GPCRs). Therefore, TRPC5 was suggested to be a receptoroperated channel (ROC). ${ }^{2-5)}$ TRPC4 and TRPC5 are rapidly desensitized after activation by GPCR. This desensitization does not depend on extracellular monovalent cations, such as $\mathrm{Na}^{+}$or $\mathrm{Cs}^{+}$. TRPC4 and TRPC5 are desensitized after the activation of muscarinic receptors. Even when intracellular GTP $\gamma \mathrm{S}$ has been used to activate TRPC4 and TRPC5, their currents are rapidly desensitized.

Activated $G$ proteins stimulate the hydrolysis of phosphatidylinositol 4,5-bisphosphate $\left(\mathrm{PIP}_{2}\right)$ through $\mathrm{PLC} \beta$. PIP $_{2}$ is then hydrolyzed into inositol 1,4,5-trisphosphate $\left(\mathrm{IP}_{3}\right)$ and diacylglycerol (DAG). Among mammalian TRPs, TRP vanilloid 1 (TRPV1) has been shown to be inactivated by PIP ${ }_{2}{ }^{6,7)}$ Alternatively, PIP ${ }_{2}$ activates TRP melastatin 5 (TRPM5), ${ }^{8)}$ TRPM7, $\left.{ }^{9}\right)$ TRPM8, ${ }^{10)}$ TRPV5, ${ }^{11)}$ and TRPC6. ${ }^{12)}$ In the TRPM4 channel, current was recovered by $\mathrm{PIP}_{2}$ after an initial decay. ${ }^{13)}$

Previously, we showed that TRPC5 is likely to be a nonselective cationic currents (NSCC) channel, activated by muscarinic receptor stimulation. ${ }^{3,14,15)}$ In subsequent studies, we showed that TRPC5 has two regulatory NSCC pathways activated by stimulation of muscarinic receptors in native tissues ${ }^{16,17)}$ : the DAG-protein kinase C (PKC) negative feedback pathway, ${ }^{16-18)}$ and the calmodulin $(\mathrm{CaM})$-myosin light chain kinase (MLCK) positive feedback pathway. ${ }^{19-21)}$

To further confirm the identity of TRPC5 as an NSCC activated by muscarinic receptor stimulation, we investigated the effects of intracellular $\mathrm{PIP}_{2}$ on TRPC5 channels expressed in human embryonic kidney (HEK) cells. We found that the desensitization of TRPC5 current is associated with both $\mathrm{PIP}_{2}$ and PKC. ${ }^{17)}$ We also determined that the actin cytoskeleton is involved in the activation and desensitization of TRPC5 currents. Additionally, in mouse ileal myocytes, $\mathrm{PIP}_{2}$ is associated with the desensitization of carbachol (CCh)-activated inward currents. These results give further evidence that TRPC5 is a candidate NSCC channel, activated by muscarinic receptor stimulation.

\section{MATERIALS AND METHODS}

Cell Culture and Transient Transfection Human embryonic kidney (HEK)293 cells (ATCC, Manassas, VA, U.S.A.) were maintained according to the recommendations of the supplier. For transient transfection, cells were seeded in 6-well plates. The following day, $1 \mu \mathrm{g} / \mathrm{well}$ pcDNA plasmid vectors containing the cDNA for TRPC5-GFP (given kindly by Dr. Shuji Kaneko) and muscarinic receptor 3 were transfected into cells using the transfection reagent FuGENE 6 (Roche Molecular Biochemicals) according to the manufacturer's protocol. After $24-48 \mathrm{~h}$, cells were trypsinized and used for whole-cell recording.

Dissociation of Single Cells from Mouse Ileum Ileal myocytes were enzymatically isolated from the ileal region of Institute for Cancer Research (ICR) mice. Mice of either sex weighing $20-30 \mathrm{~g}$ were anaesthetized with carbon dioxide and sacrificed by cervical dislocation. The ileal part of the intestine was cut out. The mucous layer was dissected from the smooth muscle layer with fine scissors and cut into small segments ( $c a .2-3 \mathrm{~mm}$ ). Segments were then digested for $25-30 \mathrm{~min}$ at $37^{\circ} \mathrm{C}$ in $\mathrm{Ca}^{2+}$-free Tyrode solution containing $0.1 \%$ collagenase (Worthington type 2 ), $0.1 \%$ dithiothreitol, $0.1 \%$ trypsin inhibitor, and $0.2 \%$ bovine serum albumin. Single myocytes were dispersed by gentle agitation of the digested segments with a wide-bored glass pipette and kept at $4{ }^{\circ} \mathrm{C}$ until use. All experiments were carried out at room temperature within $10 \mathrm{~h}$ of harvesting cells. 
Whole-Cell Patch-Clamp Recording Isolated cells were transferred to a small chamber on the stage of an inverted microscope (IX70, Olympus, Japan). Cells were continually perfused with normal Tyrode solution $(2-3 \mathrm{ml} / \mathrm{min})$. A glass microelectrode with a resistance of $3-5 \mathrm{M} \Omega$ was used to make a gigaohm seal. The conventional whole-cell patch-clamp technique was adapted to hold the membrane potential at $-60 \mathrm{mV}$ using an Axopatch 200B patch-clamp amplifier (Axon Instrument, U.S.A.). For data acquisition and the application of command pulses, pCLAMP software (v.9.2) and Digidata 1200 (Axon Instruments) were used. Data were analyzed at $5 \mathrm{kHz}$ and displayed on a computer monitor; they were analyzed using pCLAMP and Origin software (Microcal origin v.7.0, U.S.A.).

Solutions and Drugs Tyrode solution contained $135 \mathrm{~mm}$ $\mathrm{NaCl}, 5 \mathrm{~mm} \mathrm{KCl}, 2 \mathrm{~mm} \mathrm{CaCl} 2,1 \mathrm{~mm} \mathrm{MgCl}_{2}, 10 \mathrm{~mm}$ glucose, and $10 \mathrm{~mm}$ HEPES ( $N$-[2-hydroxyethyl]piperazine- $N N^{\prime}$-[2ethanesulphonic acid]). The $\mathrm{pH}$ was adjusted to 7.4 using $\mathrm{NaOH}$. Cs-rich external solution was made by replacing $\mathrm{NaCl}$ and $\mathrm{KCl}$ with equimolar $\mathrm{CsCl}$. The pipette solution contained $140 \mathrm{~mm} \mathrm{CsCl}, 10 \mathrm{~mm}$ HEPES, $0.2 \mathrm{~mm}$ Tris-GTP (Tris-guanosine $5^{\prime}$-triphospate), $0.5 \mathrm{~mm}$ ethylene glycol-bis(2-aminoethyl ether)- $N, N, N^{\prime}, N^{\prime}$-tetraacetic acid (EGTA), and $3 \mathrm{~mm} \mathrm{Mg}-\mathrm{ATP}$ (Mg-adenosine $5^{\prime}$-triphosphate). The $\mathrm{pH}$ was adjusted to 7.3 with $\mathrm{CsOH}$. Stock solutions of the DMSOsoluble drugs cytochalasin D $(5 \mathrm{~mm})$ and wortmannin (100 mm) were made. DiC8-phosphoinositides (Echelon Research Laboratories, Salt Lake City, UT, U.S.A.) were dissolved in deionised and deoxygenated water $(0.5 \mathrm{~mm})$ or directly in the pipette solution (if applied at concentrations higher than $20 \mu \mathrm{M}$ ) by a 30 -min sonication. All other drugs were obtained from Sigma (U.S.A.).

Statistics All data are expressed as means \pm S.E.M. Statistical significance was determined using Student's unpaired $t$-tests. $p$ values $<0.05$ were considered statistically significant. The number of cell recordings in each experiment is represented by $n$.

\section{RESULTS}

Effects of PIP ${ }_{2}$ on Desensitization of the TRPC5 Current Whole-cell currents were recorded using patch-clamp techniques. Initially these currents were recorded in the presence of normal Tyrode solution. Then, the external solution was changed from normal Tyrode to $140 \mathrm{~mm}\left[\mathrm{Cs}^{+}\right]_{0}$, resulting in a slight increase in basal currents, due to the constitutive activity of TRPC5. At times, currents up to $1 \mathrm{nA}$ were activated without stimulation by $\mathrm{CCh}$. Therefore, we waited at least $2 \mathrm{~min}$ before the application of $\mathrm{CCh}$. Whole-cell currents also were recorded in a solution containing $140 \mathrm{~mm}$ extracellular $\mathrm{Cs}^{+}$concentration $\left(\left[\mathrm{Cs}^{+}\right]_{0}\right)$ and $\left[\mathrm{Cs}^{+}\right]_{\mathrm{i}}$ as a control to determine the $I-V$ relationship of TRPC5 activated by $\mathrm{CCh}$. To examine $I-V$ relationships, we applied a ramp pulse from $+100 \mathrm{mV}$ to $-100 \mathrm{mV}$ for $500 \mathrm{~ms}$. When $50 \mu \mathrm{M} \mathrm{CCh}$ was added at a holding potential of $-60 \mathrm{mV}$, an inward current was activated in HEK293 cell expressing TRPC5 (Fig. 1Aa). The $I-V$ relationship, obtained by subtracting the current observed in the absence of $\mathrm{CCh}$ from the current obtained in its presence, showed a typical doubly rectifying shape (Fig. 1Ab). TRPC5 currents were not activated by $\mathrm{CCh}$ in mock transfected cells (Fig. 1B). We used only results ob-

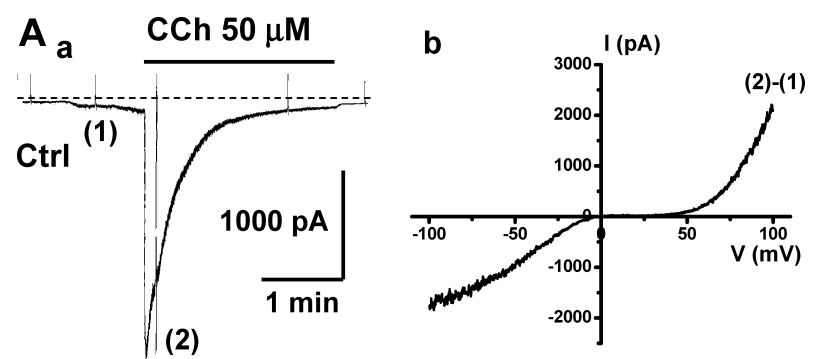

B
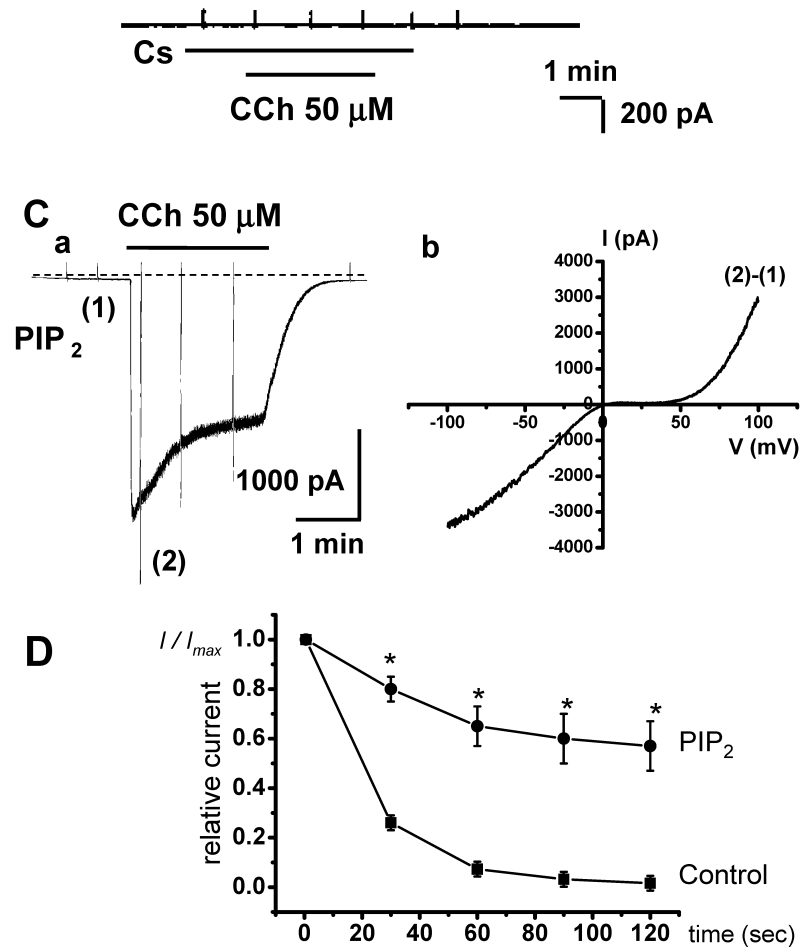

Fig. 1. The Effect of $\mathrm{PIP}_{2}$ on the Desensitization of TRPC5 Current under $140 \mathrm{~mm}$ Extracellular Cs and Intracellular Cs Condition Using the WholeCell Patch-Clamp Technique

(A) a. In control HEK293 cell expressing TRPC5, CCh $(50 \mu \mathrm{M})$ induced an inward current, which decayed spontaneously during $\mathrm{CCh}$ treatment. Slow ramp depolarizations from -100 to $+100 \mathrm{mV}$ were applied from a holding potential of $-60 \mathrm{mV}$ before (1) and during (2) $50 \mu \mathrm{M} \mathrm{CCh}$ treatment. Dashed lines show zero current. b. $I-V$ relationships were obtained by subtracting (1) from (2). $I-V$ relationships showed a typical doubly rectifying shape. (B) Whole cell currents were recorded in mock transfected cells. (C) a. In the presence of $20 \mu \mathrm{M} \mathrm{diC8-PIP}{ }_{2}$ in the pipette solution, CCh $(50 \mu \mathrm{M})$ induced an inward current, which decayed slowly during $\mathrm{CCh}$ treatment. Slow ramp depolarizations from -100 to $+100 \mathrm{mV}$ were applied from a holding potential of $-60 \mathrm{mV}$ before (1) and during (2) $50 \mu \mathrm{M} \mathrm{CCh}$ treatment. Dashed lines show zero current. b. $I-V$ relationships showed a typical doubly rectifying shape. (D) $\mathrm{CCh}$ induced inward currents were normalized against the peak amplitude and average values are plotted against time $\left(\boldsymbol{\square}\right.$, control; $\bullet$, intracellularly applied $\left.\mathrm{PIP}_{2}\right)$. Asterisks indicate significant differences $(* p<0.05)$.

tained from cells producing the typical $I-V$ relationship of TRPC5. The TRPC5 current that was activated by stimulating muscarinic receptors decayed spontaneously to basal levels, even during $\mathrm{CCh}$ application (Fig. 1Aa). This process is referred to as desensitization. Previous studies assumed that the depletion of $\mathrm{PIP}_{2}$ by the hydrolysis of $\mathrm{PIP}_{2}$ through PLC $\beta$ induces the activation of TRPC5. We first examined the role of the PLC substrate, PIP ${ }_{2}$, on the TRPC5 current. To study the effects of $\mathrm{PIP}_{2}$ on the agonist-induced TRPC5 current, we included $20 \mu \mathrm{M}$ dioctanoyl analog of $\mathrm{PIP}_{2}\left(\mathrm{diC} 8-\mathrm{PIP}_{2}\right)$, a more water-soluble short form of $\mathrm{PIP}_{2}$, in the recording pipettes. Under these conditions, CCh induced TRPC5 cur- 


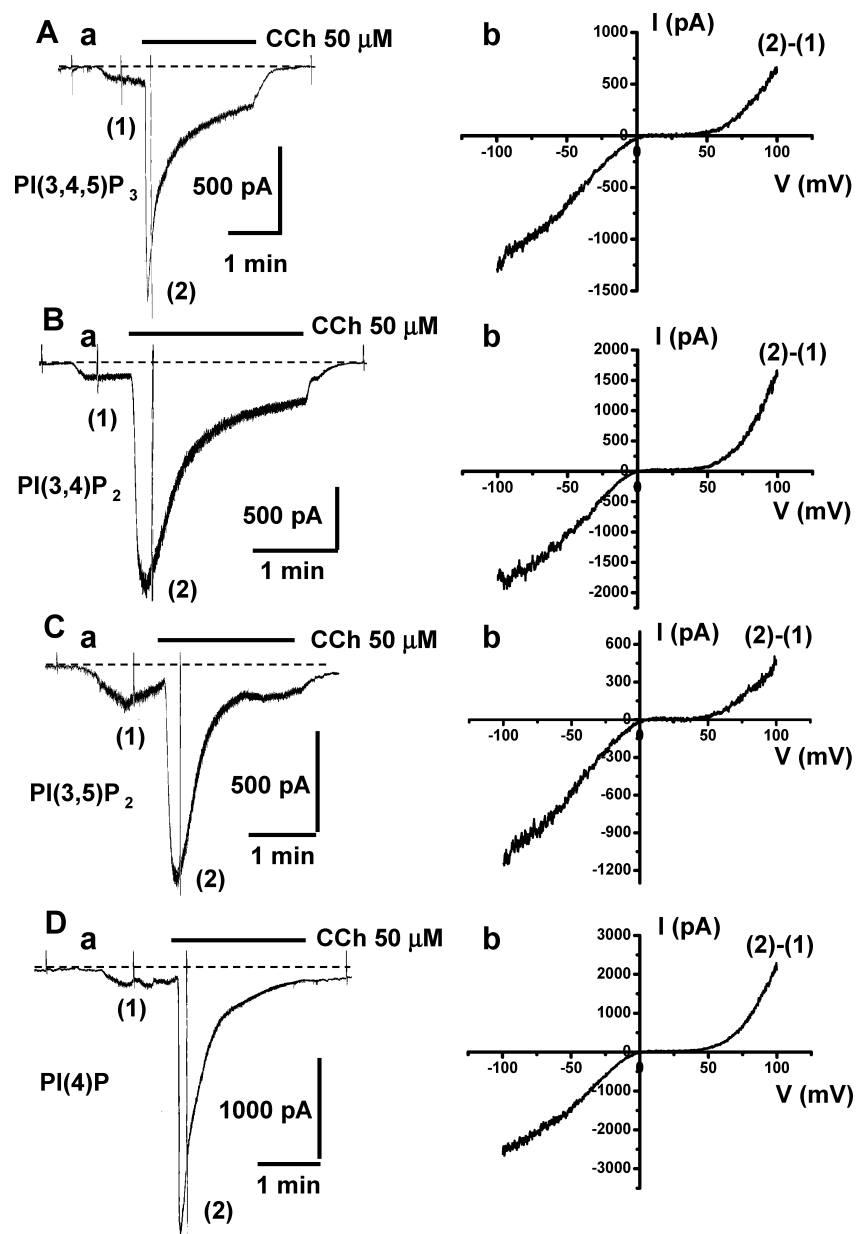

Fig. 2. The Effect of Several PIs on the Desensitization of TRPC5 Current under $140 \mathrm{~mm}$ Extracellular Cs and Intracellular Cs Condition Using the Whole-Cell Patch-Clamp Technique

(A) a. In the presence of $20 \mu \mathrm{M} \mathrm{PI}(3,4,5) \mathrm{P}_{3}$ in the pipette solution, CCh $(50 \mu \mathrm{M})$ induced an inward current, which decayed spontaneously during CCh treatment. b. $I-V$ relationships showed a typical doubly rectifying shape. (B) a. In the presence of $100 \mu \mathrm{M}$ $\mathrm{PI}(3,4) \mathrm{P}_{2}$ in the pipette solution, CCh $(50 \mu \mathrm{M})$ induced an inward current, which decayed spontaneously during $C C h$ treatment. b. $I-V$ relationships showed a typical doubly rectifying shape. (C) a. In the presence of $100 \mu \mathrm{M} \mathrm{PI}(3,5) \mathrm{P}_{2}$ in the pipette solution, $\mathrm{CCh}(50 \mu \mathrm{M})$ induced an inward current, which decayed spontaneously during $\mathrm{CCh}$ treatment. b. $I-V$ relationships showed a typical doubly rectifying shape. (D) a. In the presence of $200 \mu \mathrm{M} \mathrm{PI}(4) \mathrm{P}$ in the pipette solution, CCh $(50 \mu \mathrm{M})$ induced an inward current, which decayed spontaneously during $C C h$ treatment. b. $I-V$ relationships showed a typical doubly rectifying shape. Dashed lines show zero current.

rents, contrary to what was expected. However, the desensitization of the TRPC5 current slowed in response to CCh (Fig. $1 \mathrm{Ca})$. During desensitization, the $I-V$ relationship showed a typical doubly rectifying shape (Fig. 1Cb). In TRPC5-expressing cells, the inward current spontaneously declined to $1.6 \pm 3.0 \%$ of the initial peak amplitude found $2 \mathrm{~min}$ after CCh application $(n=20)$. In TRPC5-expressing cells included $\mathrm{PIP}_{2}$ in recording pipettes, however, the inward current remained at $57 \pm 10 \%$ of the initial peak amplitude 2 min after CCh application. There was no significant change in the activation process $(n=10)$ (Fig. 1D). The decay rates were significantly different. Montell and colleagues ${ }^{12)}$ have recently demonstrated the direct binding of several phosphoinositides (PIs) to other members of the TRP superfamily, including TRPC1, 5, 6 and 7. Therefore, we examined the effects of other phosphoinositides (PIs) on TRPC5 currents. We investigated the effect of $\mathrm{PI}(3,4,5) \mathrm{P}_{3}, \mathrm{PI}(3,4) \mathrm{P}_{2}$,
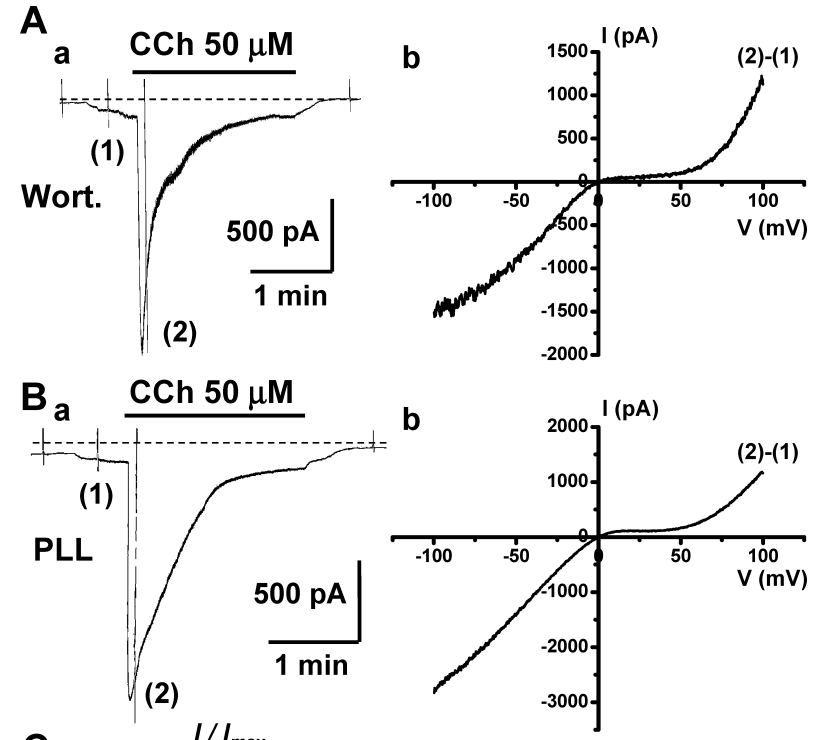

C

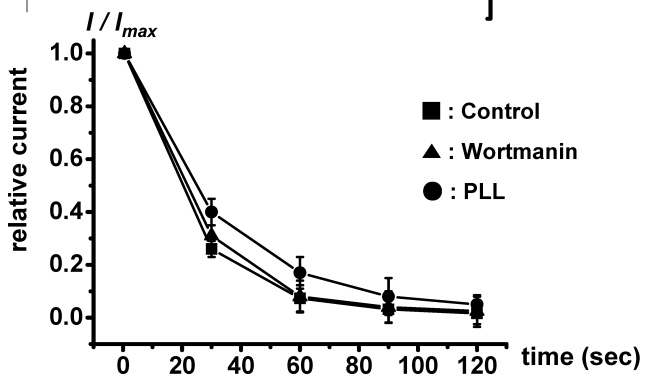

Fig. 3. The Effect of Wortmannin and Poly-L-lysine (PLL) on the Desensitization of TRPC5 Current under $140 \mathrm{~mm}$ Extracellular Cs and Intracellular Cs Condition Using the Whole-Cell Patch-Clamp Technique

(A) a. In the presence of $50 \mu \mathrm{M}$ wortmannin in the pipette solution, CCh $(50 \mu \mathrm{M})$ induced an inward current, which decayed spontaneously during CCh treatment. Dashed lines show zero current. b. $I-V$ relationships showed a typical doubly rectifying shape. (B) a. In the presence of $3 \mu \mathrm{g} / \mathrm{ml}$ PLL in the pipette solution, CCh $(50 \mu \mathrm{M})$ induced an inward current, which decayed spontaneously during $\mathrm{CCh}$ treatment. Dashed lines show zero current. b. $I-V$ relationships showed a typical doubly rectifying shape. (C) $\mathrm{CCh}$ induced inward currents were normalized against the peak amplitude and average values are plotted against time ( $\mathbf{\square}$, control; $\mathbf{\Delta}$; wortmannin; $\bullet$, PLL).

$\mathrm{PI}(3,5) \mathrm{P}_{2}$, and $\mathrm{PI}(4) \mathrm{P}$. Taking into account differences in the binding affinities, ${ }^{12)}$ PIs were applied (similarly to $\mathrm{PIP}_{2}$ ) at the following concentrations: $\mathrm{PI}(3,4,5) \mathrm{P}_{3}(n=7)$ at $20 \mu \mathrm{M}$, $\mathrm{PI}(3,4) \mathrm{P}_{2}(n=3)$ and $\mathrm{PI}(3,5) \mathrm{P}_{2}(n=4)$ at $100 \mu \mathrm{M}$, and $\mathrm{PI}(4) \mathrm{P}$ $(n=3)$ at $200 \mu \mathrm{M}$. No attenuation of desensitization was seen (Fig. 2), highlighting the specificity of the attenuation of $\mathrm{PIP}_{2}$ on the desensitization of the TRPC5 current. This result is not simply a negative charge effect of $\mathrm{PIP}_{2}$.

PIP $_{2}$ Depletion Is Not Sufficient for Full TRPC5 Desensitization Wortmannin, an inhibitor of phosphatidylinositol 4-kinase, retards the replenishment of $\mathrm{PIP}_{2}$, which leads to depletion of the intracellular $\mathrm{PIP}_{2}$ pool. ${ }^{22}$ In the whole-cell mode, $50 \mu \mathrm{M}$ wortmannin in the pipette solution had no effect on desensitization of the TRPC5 current (Fig. 3Aa) or on the typical doubly rectifying $I-V$ shape (Fig. 3Ab). Poly-L-lysine (PLL) is a positively charged macromolecule that acts as a scavenger of $\mathrm{PIP}_{2}{ }^{23,24)}$ and inhibits the activity of the $\mathrm{PIP}_{2}$-activated TRPM4 and TRPM8 channels. ${ }^{13,25)}$ However, $3 \mu \mathrm{g} / \mathrm{ml}$ PLL in the pipette solution did not cause any significant change in desensitization of the TRPC5 current (Fig. 3Ba) or the typical doubly rectifying $I-V$ shape (Fig. $3 \mathrm{Bb}$ ). In TRPC5-expressing cells, the desensitization of the TRPC5 current, by the addition of wortmannin and PLL to the 

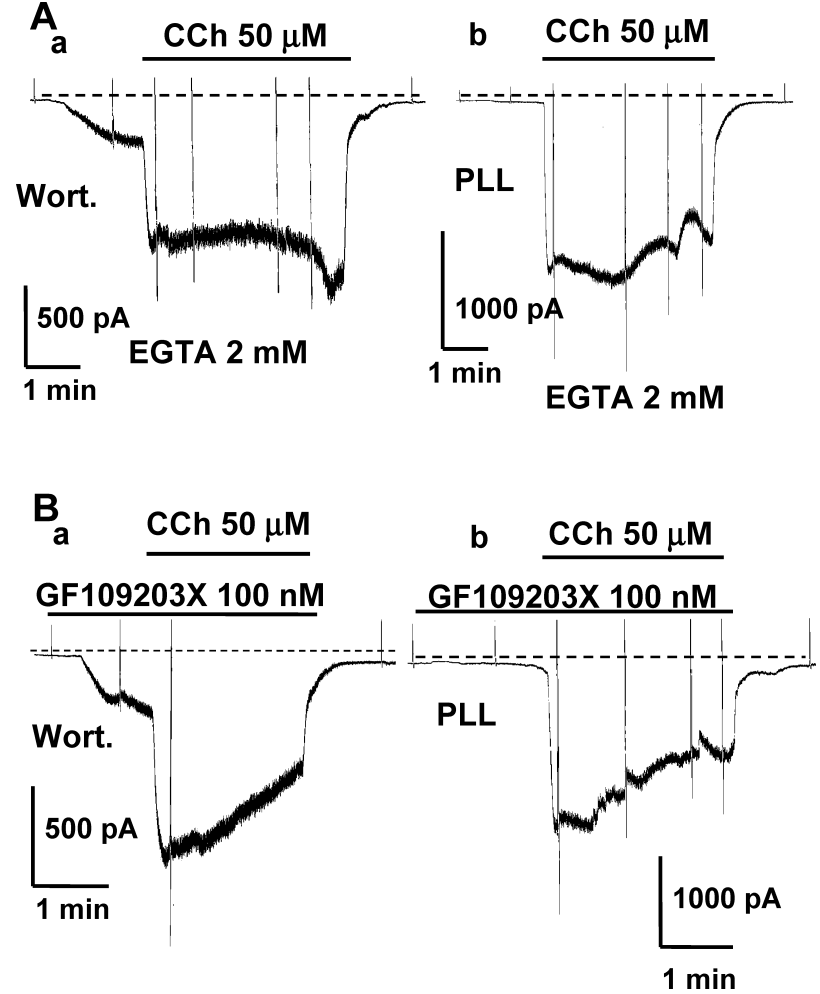

Fig. 4. The Effect of Wortmannin and Poly-L-lysine (PLL) on the Desensitization of TRPC5 Current under EGTA 2 mM Pipette Solution or PKC Inhibitor in Bath Solution

(A) In the presence of $50 \mu \mathrm{M}$ wortmannin (a) or $3 \mu \mathrm{g} / \mathrm{ml}$ PLL (b) in the pipette solution (EGTA $2 \mathrm{~mm}), \mathrm{CCh}(50 \mu \mathrm{M})$ induced an inward current, which slowed desensitization during CCh treatment. (B) In the presence of $50 \mu \mathrm{M}$ wortmannin (a) or $3 \mu \mathrm{g} / \mathrm{m}$ PLL (b) in the pipette solution or PKC inhibitor GF109203X $100 \mathrm{~nm}$ in bath solution, $\mathrm{CCh}(50 \mu \mathrm{M})$ induced an inward current, which slowed desensitization during CCh treatment.

recording pipettes, had no significant effects $(n=5)$ (Fig. 3C). Zhu et al. ${ }^{17)}$ reported that EGTA, depletion of Mg-ATP, or PKC inhibitor slows the desensitization. Therefore, we examined the effect of wortmannin and PLL on desensitization of the TRPC5 current in the presence of EGTA or PKC inhibitor. In this paper, we performed all experiments with internal solution containing $0.5 \mathrm{~mm}$ EGTA. In an internal solution containing $2 \mathrm{~mm}$ EGTA, the desensitization of TRPC5 current was attenuated. ${ }^{17)}$ When we applied wortmannin or PLL in $2 \mathrm{~mm}$ EGTA pipette solution, there was no effect of wortmannin or PLL on desensitization of TRPC5 current (Fig. 4A). PKC inhibitor slowed the desensitization of TRPC5 current. ${ }^{17)}$ When we applied wortmannin or PLL in pipette solution and PKC inhibitor in bath solution, there was no effect of wortmannin or PLL on desensitization of TRPC5 current (Fig. 4B). These data demonstrate that PIP $_{2}$ blockade of the TRPC5 current desensitization is necessary but not sufficient for the full desensitization of the TRPC5 current.

The Role of the Actin Cytoskeleton on TRPC5 Current $\mathrm{PIP}_{2}$ interacts with cytoskeletal proteins and anchors various signalling molecules to the plasma membrane. ${ }^{26,27)}$ Proteins involved in cytoskeletal remodeling are important targets of $\mathrm{PIP}_{2}$ signalling. Therefore, we investigated whether the association of $\mathrm{PIP}_{2}$ with the actin cytoskeleton has a role in $\mathrm{PIP}_{2}$ regulation of desensitization of the TRPC5 current. TRPC5expressing cells were treated with $0.5 \mu \mathrm{M}$ cytochalasin $\mathrm{D}$, a potent cell permeable fungal toxin, which inhibits actin
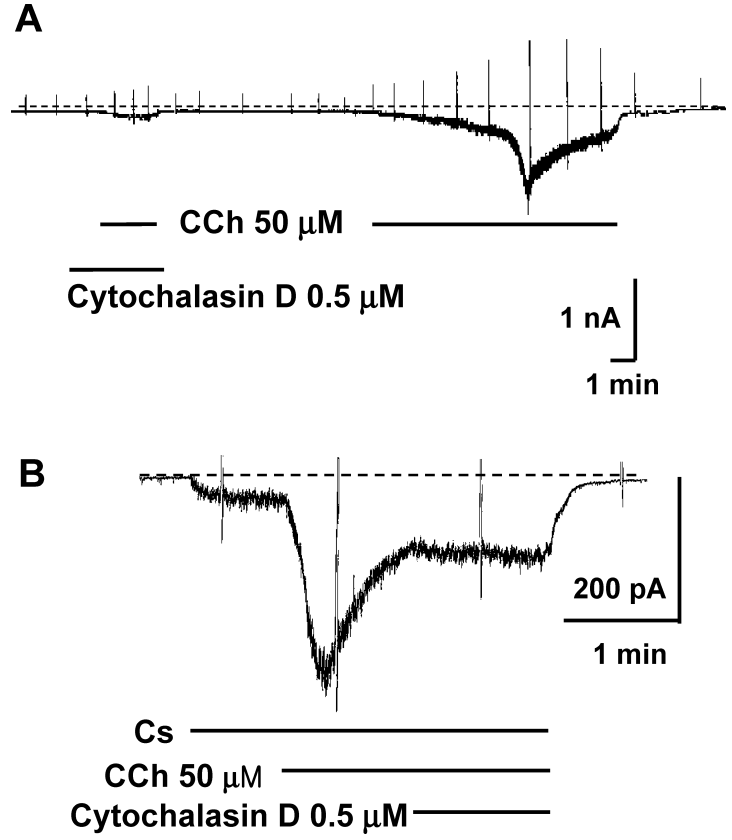

Fig. 5. The Effect of Actin Cytoskeleton Inhibitor on TRPC5 Current

(A) $\mathrm{CCh}(50 \mu \mathrm{M})$ did not induce an inward current in the presence of $0.5 \mu \mathrm{M}$ cytochalasin D. However, CCh activated inward current after washout of cytochalasin D. (B) Cytochalasin D inhibited the desensitization of TRPC5 current when added after activation of the TRPC5 current. Dashed lines show zero current.

polymerization and thus disrupts actin microfilaments. Cytochalasin D completely inhibited the activation of the TRPC5 current (Fig. 4), such that it was impossible to investigate whether the association of $\mathrm{PIP}_{2}$ with the actin cytoskeleton has a role in regulating desensitization of this current And cytochalasin D also inhibited the desensitization of TRPC5 current when it was added after the activation of TRPC5 current (Fig. 5B). These results suggest that the cytoskeleton is involved in both activation and desensitization of TRPC5 current.

PIP $_{2}$ Attenuates Desensitization of the CCh-Activated Current $\left(I_{\mathrm{CCh}}\right)$ in Mouse Ileal Myocyte Since $I_{\mathrm{CCh}}$ appears to be largely mediated by TRPC $5,{ }^{3,21)}$ it was important to determine whether desensitization of $I_{\mathrm{CCh}}$ depends on $\mathrm{PIP}_{2}$. CsCl-rich solutions were used in both the pipette and bath to record $I_{\mathrm{CCh}}$. Under a voltage clamp, at a holding potential of $-60 \mathrm{mV}, 50 \mu \mathrm{M}$ CCh induced $I_{\mathrm{CCh}}$. Spontaneous decay of $I_{\mathrm{CCh}}$ (desensitization of $\left.I_{\mathrm{CCh}}\right)$ occurred $(n=5$, Fig. 5Aa). To determine the $I-V$ relationship, we applied a ramp pulse from +100 to $-100 \mathrm{mV}$ for $500 \mathrm{~ms}$. The $I-V$ relationship showed a typical doubly rectifying shape (Fig. $5 \mathrm{Ab}$ ). In the presence of $20 \mu \mathrm{M} \mathrm{diC} 8-\mathrm{PIP}_{2}$ in the pipette solution, the desensitization of $I_{\mathrm{CCh}}$ slowed (Fig. 5Ba). During desensitization, the $I-V$ relationship showed a typical doubly rectifying shape (Fig. 5Bb). In control mouse ileal myocytes, the inward current spontaneously declined to $7.1 \pm 3.1 \%$ of the initial peak amplitude after $2 \mathrm{~min}$ of $\mathrm{CCh}$ application $(n=5)$. In the presence of $20 \mu \mathrm{M} \mathrm{diC} 8-\mathrm{PIP}_{2}$ in the pipette solution, however, the inward current remained at $64 \pm 5.1 \%$ of the initial peak amplitude 2 min after $\mathrm{CCh}$ application. There was no change in the activation process $(n=5)$ (Fig. 5C). These results suggest that TRPC5 is a candidate NSCC, activated by muscarinic receptor stimulation in gastrointestinal smooth muscle cells. 


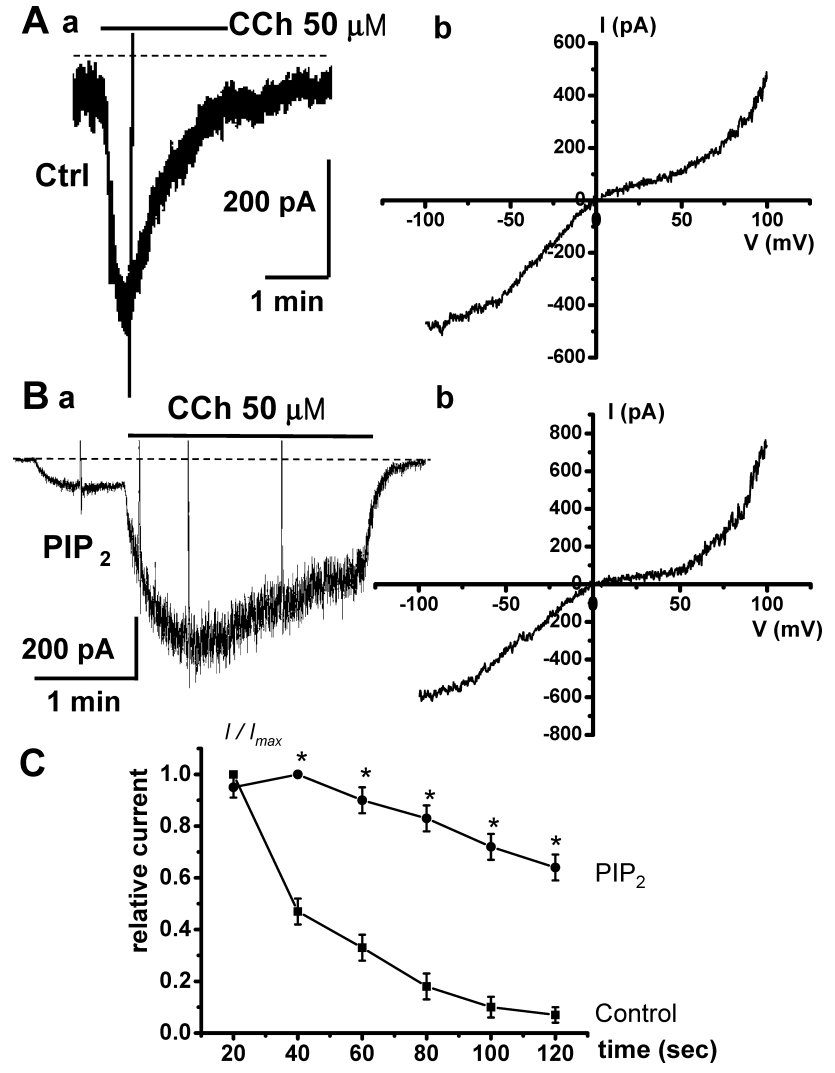

Fig. 6. The Desensitization of CCh-Activated Inward Current and Its $I-V$ Relationship Recorded from Murine Ileal Myocytes Using the Whole-Cell Patch-Clamp Technique

(A) a. Whole cell currents were recorded under the condition of $140 \mathrm{~mm}\left[\mathrm{Cs}^{+}\right]_{\mathrm{i}} \cdot \mathrm{CCh}$ $(50 \mu \mathrm{M})$ induced an inward current, which decayed spontaneously during CCh treatment. Slow ramp depolarizations from +100 to $-100 \mathrm{mV}$ were applied at a holding potential of $-60 \mathrm{mV}$. Dashed lines show zero current. b. $I-V$ relationships showed a typical doubly rectifying shape. (B) a. In the presence of $20 \mu \mathrm{M} \mathrm{diC8}-\mathrm{PIP}_{2}$ in the pipette solution, CCh $(50 \mu \mathrm{M})$ induced an inward current, which decayed slowly during $\mathrm{CCh}$ treatment. Dashed lines show zero current. b. $I-V$ relationships showed a typical doubly rectifying shape. (C) $\mathrm{CCh}$ induced inward currents were normalized against the peak amplitude and average values are plotted against time $(\boldsymbol{\square}$, control; $\bullet$, intracellularly applied $\left.\mathrm{PIP}_{2}\right)$. Asterisks indicate significant differences $(* p<0.05)$

\section{DISCUSSION}

We have demonstrated that intracellularly-applied $\mathrm{PIP}_{2}$ attenuated the desensitization of TRPC5 currents. We have also shown that the actin cytoskeleton plays a role in the activation and the desensitization of these currents. Moreover, we have shown that in mouse ileal myocytes, the desensitization of $I_{\mathrm{CCh}}$ also slowed when $\mathrm{PIP}_{2}$ was included in the recording pipettes. These results suggest that $\mathrm{PIP}_{2}$ is involved in the desensitization of TRPC5 currents and that TRPC5 is still a candidate NSCC channel, activated by muscarinic receptor stimulation.

Among the isolated TRP channels, TRPC4 and TRPC5 are in the same group. Recently, Otsuguro et al. ${ }^{28)}$ suggested that TRPC $4 \alpha$, but not TRPC $4 \beta$, was strongly inhibited by intracellularly applied $\mathrm{PIP}_{2}$, and that its inhibitory action was dependent on the association of TRPC $4 \alpha$ with actin cytoskeleton. Its inhibitory action was prevented by the application of cytochalasin $\mathrm{D}$ or the deletion of the C-terminal PDZ binding motif (Thr-Thr-Arg-Leu), which links TRPC4 to F-actin through NHERF and ezrin. ${ }^{28)}$ The activation kinetics of rat TRPC5 was modulated by the scaffolding protein ezrin/ radixin/moesin-binding phosphoprotein-50 (EBP50). ${ }^{29)} \mathrm{PIP}_{2}$ did not inhibit TRPC5 current although TRPC5 was most similar at the amino acid sequence to TRPC $4 \alpha$ (Fig. 1C). On the contrary, $\mathrm{PIP}_{2}$ slowed the desensitization process of TRPC5. In our previous study, we showed the desensitization depended upon PKC phosphorylation of TRPC5 channel. ${ }^{17}$ $\mathrm{PIP}_{2}$ scavenger, PLL or wortmannin, did not reverse the inhibition of the desensitization of TRPC5 by PKC inhibitor (Fig. 4B). We suggest that PKC might be the downstream target of $\mathrm{PIP}_{2}$ rather than acting independently of $\mathrm{PIP}_{2}$. In TRPC5, cytochalasin D inhibited the activation and the desensitization of these current (Fig. 5). We already showed that MLCK is involved in the activation process of TRPC5 channel, ${ }^{20)}$ while other research showed that actin is linked with TRPC4 and TRPC5 through NHERF and ezrin. The effect of cytochalasin D on both activation and desensitization suggest that TRPC5 channel exists as a multi-proteins complex and actin has important roles for activation and desensitization of TRPC5 channel.

In our examination of TRPC5, however, intracellularly applied $\mathrm{PIP}_{2}$ attenuated the desensitization of TRPC5 currents. Additionally, we showed that the actin cytoskeleton had a role in activation and desensitization of these currents. In our previous study, the deletion of the C-terminal PDZ binding motif (Thr-Thr-Arg-Leu) inhibited the activation of TRPC4 and TRPC5 channels expressed in HEK cells ${ }^{17)}$ and slowed the activation of rat TRPC $5 .{ }^{29)}$ We determined that attenuation of the desensitization of TRPC 5 current was specific to $\mathrm{PIP}_{2}$, as other PIs had no effect. This indicates that the effects are not simply a negative charge effect, as in the case of activation of the TRPC 4 current. ${ }^{28)}$

Lee $e t a l .{ }^{3)}$ suggested that TRPC5 was a promising candidate for muscarinic cationic channel in murine gastric myocytes. As the properties of $I_{\mathrm{CCh}}$ in murine ileal myocytes are consistent with a previous report about nonselective cation channels activated by muscarinic stimulation in murine gastric myocytes ${ }^{30)}$ TRPC5 may also be a promising candidate for muscarinic cationic channel in murine ileal myocytes. The effect of CaM and MLCK on murine ileal myocytes was similar to that of TRPC5, suggesting TRPC5 to be a candidate for NSCC, activated by muscarinic stimulation. ${ }^{20,21)}$ In the present study, the desensitization of $I_{\mathrm{CCh}}$ in mouse ileal myocytes also slowed when PIP $_{2}$ was included in recording pipettes.

In conclusion, $\mathrm{PIP}_{2}$ is involved in the desensitization of TRPC5 currents. TRPC5 remains a candidate for NSCC channel which is activated by muscarinic receptor stimulation.

Acknowledgement This work was supported by the Creative Research Initiative Center for Bio-Artificial Muscle of the Ministry of Science \& Technology (MOST) and the Korea Science and Engineering Foundation (KOSEF).

\section{REFERENCES}

1) Philipp S., Hambrecht J., Braslavski L., Schroth G., Freichel M., Murakami M., Cavalie A., Flockerzi V., EMBO J., 17, 4274-4282 (1998).

2) Kanki H., Kinoshita M., Akaike A., Satoh M., Mori Y., Kaneko S. Mol. Pharmacol., 60, 989-998 (2001).

3) Lee Y. M., Kim B. J., Kim H. J., Yang D. K., Zhu M. H., Lee K. P., So 
I., Kim K. W., Am. J. Physiol. Gastrointest. Liver Physiol., 284, G604-G616 (2003).

4) Ohta T., Morishita M., Mori Y., Ito S., Neurosci. Lett., 358, 161-164 (2004).

5) Venkatachalam K., Zheng F., Gill D. L., J. Biol. Chem., 278, 2903129040 (2003)

6) Chuang H. H., Prescott E. D., Kong H., Shields S., Jordt S. E., Basbaum A. I., Chao M. V., Julius D., Nature (London), 411, 957-962 (2001).

7) Prescott E. D., Julius D., Science, 300, 1284-1288 (2003).

8) Liu D., Liman E. R., Proc. Natl. Acad. Sci. U.S.A., 100, 15160-15165 (2003).

9) Runnels L. W., Yue L., Clapham D. E., Nat. Cell. Biol., 4, 329-336 (2002).

10) Liu B., Qin F., J. Neurosci., 25, 1674-1681 (2005).

11) Lee J., Cha S. K., Sun T. J., Huang C. L., J. Gen. Physiol., 126, 439451 (2005).

12) Kwon Y., Hofmann T., Montell C., Mol. Cell, 25, 491-503 (2007).

13) Nilius B, Mahieu F., Prenen J., Janssens A., Owsianik G., Vennekens R., Voets T., EMBO J., 25, 467-478 (2006).

14) Lee K. P., Jun J. Y., Chang I. Y., Suh S. H., So I., Kim K. W., Mol. Cells, 20, 425-431 (2005).

15) Kim M. J., Jeon J. P., Kim H. J., Kim B. J., Lee Y. M., Choe H., Jeon J. H., Kim S. J., So I., Biochem. Biophys. Res. Commun., 365, 239-245 (2008).

16) Ahn S. C., Kim S. J., So I., Kim K. W., Pflugers Arch., 434, 505-507 (1997).

17) Zhu M. H., Chae M., Kim H. J., Lee Y. M., Kim M. J., Jin N. G., Yang D. K., So I., Kim K. W., Am. J. Physiol. Cell Physiol., 289, C591-
C600 (2005)

18) Kim Y. C., Kim S. J., Kang T. M., Suh S. H., So I., Kim K. W., Pflugers Arch., 434, 346-353 (1997).

19) Kim Y. C., Kim S. J., Sim J. H., Jun J. Y., Kang T. M., Suh S. H., So I., Kim K. W., Pflugers Arch., 436, 1-8 (1998).

20) Kim M. T., Kim B. J., Lee J. H., Kwon S. C., Yeon D. S., Yang D. K., So I., Kim K. W., Am. J. Physiol. Cell Physiol., 290, C1031-C1040 (2006).

21) Kim B. J., Jeon J. H., Kim S. J., So I., Can. J. Physiol. Pharmacol., 85, 1254-1262 (2007)

22) Nakanishi S., Catt K. J., Balla T., Proc. Natl. Acad. Sci. U.S.A., 92 5317-5321 (1995)

23) Lopes C. M., Zhang H., Rohacs T., Jin T., Yang J., Logothetis D. E., Neuron, 34, 933-944 (2002).

24) Zhang H., Craciun L. C., Mirshahi T., Rohacs T., Lopes C. M., Jin T., Logothetis D. E., Neuron, 37, 963-975 (2003).

25) Liu B., Qin F., J. Neurosci., 25, 1674-1681 (2005).

26) Bretscher A., Chambers D., Nguyen R., Reczek D., Annu. Rev. Cell Dev. Biol., 16, 113-143 (2000).

27) McLaughlin S., Wang J., Gambhir A., Murray D., Annu. Rev. Biophys. Biomol. Struct., 31, 151-175 (2002).

28) Otsuguro K. I., Tang J., Tang Y., Xiao R., Freichel M., Tsvilovskyy V., Ito S., Flockerzi V., Zhu M. X., Zholos A. V., J. Biol. Chem., 283 $10026-10036$ (2008).

29) Obukhov A. G., Nowycky M. C., J. Cell. Physiol., 201, 227-235 (2004).

30) Dresviannikov A. V., Bolton T. B., Zholos A. V., Br. J. Pharmacol., 149, 179-187 (2006). 